\title{
3
}

\section{The Limits of Management by Objectives}

\begin{abstract}
Many companies today experience a critical strategic contradiction. Their corporate purpose and values have evolved into what could be described as a humanistic vision while, at the same time, their management systems, mostly built around management by objectives (MBO), are designed to maximize shareholder value. Everything-customer service, talent development, even their philanthropy-is a means to increase profit. The problem is not about the objectives themselves, but rather their widespread misuse through the $\mathrm{MBO}$ system. Judging by the results of four decades of research, $\mathrm{MBO}$ has not been able to bring employees' full potential into play. In this chapter, we analyze the limits of management by objectives and their consequences at organizational and personal levels.
\end{abstract}

Keywords Goals • Management by objectives • Commitment • Management by missions

The sponsors are: DPMC Foundation \& Chair in Management by Missions and Corporate Purpose (UIC) 
At present, many companies are full of contradictions. Their corporate purpose and values have evolved into what could be described as a humanistic vision, one where the company is seen as a human institution serving society, "the natural product of certain social needs." At the same time, their management systems, mostly built around management by objectives (MBO), are designed to maximize shareholder value. Everything else-customer service, talent development, even their philanthropy - is a means to increase profit. ${ }^{2}$ When the cultural dimension is detached from the everyday reality of management, it hurts the company in terms of both reputation and unity.

For centuries, it was not necessary to have talent that was fully committed to the enterprise. Companies just needed to have and retain the necessary manpower, including management, at an adequate motivational level. This objective was achieved by planning for talent needs in the short and medium terms, and offering a system of financial incentives above the market level. But competitive dynamics have increasingly required that employees feel a sense of ownership, so that they behave more like entrepreneurs and less like a salaried worker.

To achieve this level of commitment, a variety of management tools have been proposed to enrich $\mathrm{MBO}$. These include the balanced scorecard, competency management, change management programs, employee experience metrics and so on. Yet, still, something is not quite working. There remains a veiled resistance to change in which financial objectives are ultimately the deciding factor. The results are often disappointing: cultural improvement changes take time to implement and therefore the returns are hard to quantify.

The underlying challenge is to ensure that such management tools do not undermine the financial results and are consistent with the organization's purpose. And what group of workers would feel enthusiasm or commitment toward a business whose main focus is shareholder profits, unless they themselves are shareholders? In the last century, several forms

\footnotetext{
${ }^{1}$ T.J. Peters and R.H. Waterman, In Search of Excellence, op. cit.

${ }^{2}$ Jaap W. Winter, 'Dehumanization of the Large Corporation', working paper, University of Amsterdam, 10 January 2020. Available at: https://papers.ssrn.com/sol3/papers.cfm?abstract_ id=3517492. [Referenced: 11/9/2020]
} 
of employee shareholder were tested, namely cooperatives and stock options. With rare exceptions (which are more about culture than incentive), these forms of engagement have not been very successful.

Because they are deeply rooted in $\mathrm{MBO}$, these new tools do not generate commitment; they just refine the traditional top-down pressure of $\mathrm{MBO}$. This pressure, when perceived as a threat, has a negative and paralyzing effect. People tend to take refuge and defend themselves against the pressures from above by creating buffers (or safe spaces) so they can keep performing at the expected level (i.e., to achieve the established objectives... in yet another refined exercise of fulfillment and selfdeception). This deviation between expected and actual behaviors leads us to conclude that the underlying philosophy of $\mathrm{MBO}$ does not adequately address the social dynamics we see today.

\section{The Problems with Management by Objectives}

As we saw in Chap. 2, MBO was a major step forward from the purely mechanistic vision of the company in the nineteenth century. This management method is designed to produce autonomous behavior that promotes initiative and creativity to the company's benefit. In theory, it should bring out all of the human potential that was rendered useless by management due to "command and control" approach. Despite research has uncovered some limitations of $\mathrm{MBO}$ - such as its tendency to distance the company from the market, ${ }^{3}$ promotion of unethical behavior ${ }^{4}$ and diminished performance in uncertain environments ${ }^{5}$ - there is considerable empirical evidence from more than 50 years that generally

\footnotetext{
${ }^{3}$ C. Aranda, J. Arellano and A. Dávila, "Organizational Learning in Target Setting," Academy of Management Journal, vol. 60, no. 3, 2017, pp. 1189-1211.

${ }^{4}$ K. Niven and C. Healy, “Susceptibility to the 'Dark Side' of Goal-Setting: Does Moral Justification Influence the Effect of Goals on Unethical Behaviour?" Journal of Business Ethics, vol. 137, no. 1, 2016, pp. 115-127. / M.E. Schweitzer, L. Ordóñez and B. Douma, "Goal Setting as a Motivator of Unethical Behavior," Academy of Management Journal, vol. 47, no. 3, 2004, pp. 422-432.

${ }^{5}$ R. Harms, C.H. Reschke, S. Kraus and M. Fink, "Antecedents of Innovation and Growth: Analysing the Impact of Entrepreneurial Orientation and Goal-Oriented Management," International Journal of Technology Management, vol. 52, no. 1-2, 2010, pp. 135-152.
} 
corroborates the effectiveness of having goals at both the individual ${ }^{6}$ and team levels. ${ }^{7}$ Ultimately, as the research consistently showcases, having goals is better than not having goals. ${ }^{8}$

However, when $\mathrm{MBO}$ is applied in an organization with low levels of commitment, individuals tend to "game the system" by hiding behind the objectives or sticking to just fulfilling the minimum requirement. A typical example would be a sales rep who is expected to sell 100 units of a given product (say, cars). If they have already hit their target by November, they have two options: take a month's vacation, or sell more cars. A good rep will carry on selling, but they will see to it that those "extra" sales do not show up until January. Why? Because if they tell their boss that they have sold 115 cars this year, then next year's target will be 120 , and the sales rep doesn't want to risk having such a high target. Instead, they will go to their boss in January with the target of 100 already met (and with 15 more sales lined up, to be reported once they have negotiated a lower target for next year).

It is not only at the lower levels of the organization that people try to give themselves this sort of "sandbag." The sales rep's boss is very likely to have his or her own sandbag and so on upward. The consequence is that no manager three levels up knows what is really happening on the ground (much less a senior executive in a large corporation). Despite this, top management still tries-however hit-or-miss - to get the most out of the people below them, because they, too, are under pressure (and they, too, need to build a sandbag with respect to the shareholders).

In these circumstances, instead of eliciting the greatest possible contribution from all employees, the system flounders in a vicious circle of wrangling over objectives. Employees will try to talk the objectives down, while top management will try to talk them up. Usually, the conflict is resolved by mandate from above and external monitoring. This is a weakness of MBO that was noted as early as the 1950s by Drucker himself:

${ }^{6}$ E.A. Locke and G.P. Latham, "Building a Practically Useful Theory of Goal Setting and Task Motivation: A 35-Year Odyssey," American Psychologist, vol. 57, no. 9, 2002, p. 705.

${ }^{7}$ C. Antoni, "Management by Objectives: An Effective Tool for Teamwork?" The International Journal of Human Resource Management, vol. 16, no. 2, 2005, pp. 174-184.

${ }^{8}$ E.A. Locke and G.P. Latham, "Breaking the Rules: A Historical Overview of Goal-Setting Theory," Advances in Motivation Science, vol. 2, 2015, pp. 99-126. 
"The new ability to produce measuring information will make possible effective self-control; and if so used, it will lead to a tremendous advance in the effectiveness and performance of management. But if this new ability is abused to impose control on managers from above, the new technology will inflict incalculable harm by demoralizing management and by seriously lowering the effectiveness of managers."

The problem is not with the objectives themselves, but rather their widespread misuse through the $\mathrm{MBO}$ system. For many companies, $\mathrm{MBO}$ is in fact an outdated system that cannot be expected to deliver more than incremental improvements on previous years' results. What's more, $\mathrm{MBO}$ has no answer to the question of employee commitment, as it is based on a dynamic that has no use for commitment. MBO establishes a direct relationship between system pressure and system performance (see Fig. 3.1): to get more profit, I have to use more pressure

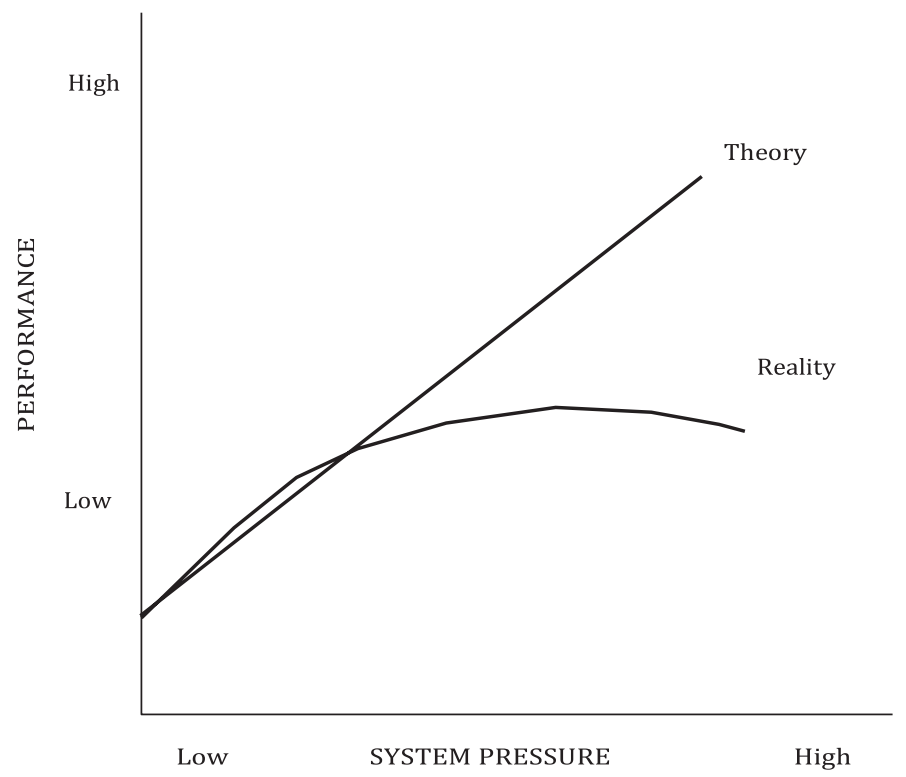

Fig. 3.1 Performance \& system pressure

${ }^{9}$ P. Drucker, The Practice of Management, op. cit., p. 132. 
(which means higher incentives and harsher punishments). In the real world, however, this is true only for a while. Once the pressure reaches a certain level, people "take cover." And if the pressure is too high, they may even start to boycott the whole system. The most serious problem is that $\mathrm{MBO}$ can only increase results by increasing the pressure. And when the system is wound too tight, something may snap.

We can see this play out in the studies by Aranda, Arellano and Dávila, who, for four years, studied the rapid growth of a travel company that went from 244 to 390 agencies. In their comparison, they observed that $\mathrm{MBO}$ had a positive effect on the newer agencies (stimulating ambitious goals) but not on the mature agencies. This was because, over time, the agencies tended to decrease their commitment to the market and set targets based solely on the previous year's results.

Judging by the results we see every day, $\mathrm{MBO}$ - even with empowerment-has not brought an employees' full potential into play. The main reason is that, without intense commitment, giving people more responsibility or power is futile; $\mathrm{MBO}$ becomes just another way of controlling someone. In our opinion, although $\mathrm{MBO}$ and empowerment represent a major step forward in management, they get results only insofar as employees are committed. As mentioned, the challenge today is not so much empowerment, but ownership: the sense of belonging, and the sense of purpose. Another consequence of $\mathrm{MBO}$ is that, given enough time and pressure, it eventually leads to a breakdown in communication within the company. In theory, $\mathrm{MBO}$ is intended to enhance communication and understanding up and down the hierarchy and across departments or units. The reality is rather opposite. People are constantly telling us: "I can't get through to my boss" (obviously not because the phone is out of order); "we work in silos"; "what we need is a bit more teamwork"... The inflexibility of personal and departmental goals ends up creating a lack of cooperation between people and departments. This is because the goals are not geared toward the common good, but rather individual gain. Additionally, more and more research shows that pressure to achieve results ultimately hurts performance. For example, the studies of Heidi K. Gardner on 78 auditing and consulting teams show a 
negative relationship between pressure and willingness to cooperate. ${ }^{10}$ In a recent study, Michael S. Gary et al. show that there is a negative effect on commitment and performance when the bosses impose the objectives. ${ }^{11}$

Clearly, the problem is not the objectives themselves, but rather how they are used and, moreover, why they are used. A fundamental limitation of $\mathrm{MBO}$ is that it was not built to create a sense of purpose. When there is no awareness of a shared purpose, $\mathrm{MBO}$ can slowly break a company apart: up, down and across the organization. On every rung of the hierarchical ladder, MBO creates potential enemies: the boss puts pressure on their subordinates and disbelieves everything they say. Subordinates do what they can to shield themselves and evade pressure at every turn. These subordinates themselves are bosses to other, lower-level employees. And the same dynamic plays out again and again.

Across the organization, MBO also creates potential enemies among those who share interdependencies or processes. Sales, for example, might complain that Production is too inflexible. While Production complains that Planning gets its forecasts wrong. And Planning complains that Sales doesn't feed the data on time. The company is fissured and increasingly unmanageable. Seventy years on, we are still banging our heads against Chester I. Barnard's tautology: "Willingness to cooperate [...] cannot develop without an objective of cooperation." 12

The limits of $\mathrm{MBO}$ have been discussed by various experts, including W.E. Deming, one of the best-known advocates of quality systems:

The idea of merit rating is alluring. The sound of the words captivates the imagination: pay for what you get; get what you pay for; motivate people to do their best, for their own good. The effect is exactly the opposite of what the words promise. Everyone propels himself forward, or tries to, for his own good, on his own life preserver. The organization is the loser. ${ }^{13}$

\footnotetext{
${ }^{10}$ H.K. Gardner, "Performance Pressure as a Double-Edged Sword: Enhancing Team Motivation but Undermining the Use of Team Knowledge," Administrative Science Quarterly, vol. 57, no. 1, May 2012, pp. 1-46.

${ }^{11}$ M.S. Gary, M.M. Yang, P.W. Yetton and J.D. Sterman, "Stretch Goals and the Distribution of Organizational Performance," Organization Science, vol. 28, no. 3, 2017, pp. 395-410.

${ }^{12}$ Chester I. Barnard, The Functions of the Executive, op. cit., p. 86.

${ }^{13} \mathrm{~W}$. Edwards Deming, Out of the Crisis, Massachusetts Institute of Technology, Center for Advanced Engineering Study (MIT CAES), Cambridge, MA, 1986, p. 102.
} 
Along with these challenges, brought on by its misuse, we now face another increasingly important limitation: the inability of $\mathrm{MBO}$ to adapt to uncertain and changing environments. $\mathrm{MBO}$ is structured into the company's budget system, which is usually annual. As the year progresses and circumstances change, the objectives may prove too big or too small, or become meaningless. In these cases, the budget becomes the main inhibitor of innovation: there is no budget for new ideas; although money can be spent on unimportant things, simply because "it's in the budget," and if we don't spend it, they will take it from us next year.

This evidence can be seen, for example, in Harms' studies of Germanbased tech companies. ${ }^{14}$ For four years, the researcher analyzed the evolution of 165 startups subjected to high uncertainty and rapid growth. Surveys conducted with managers and founders, contrasted with financial data, showed that there was no difference in economic results between companies with or without $\mathrm{MBO}$ and that, in the case of the former, MBO had a negative effect on their innovation capacity. The recent COVID-19 crisis has clearly highlighted this reality for a great number of companies. For many of them, with double-digit revenue losses in a matter of days and a situation of total uncertainty, MBO quickly ceased to be a valid approach.

These findings are starting to show that the effectiveness of $\mathrm{MBO}$ in the twentieth century may not be the same in a new era rife with uncertainty, disruption and constant change, not to mention a growing concern among the younger generations about the meaning of their work and the social impact of business. Recently, some authors have suggested improvements to $\mathrm{MBO}$ such as more frequent revision of objectives or greater transparency, ${ }^{15}$ but, in our opinion, these solutions are not enough. As we have already highlighted, the challenge is not the objectives themselves, but how they are used (control vs. autonomy), how they adapt to the context of the company (stable vs. uncertain)

\footnotetext{
${ }^{14}$ R. Harms, C.H. Reschke, S. Kraus and M. Fink, "Antecedents of Innovation and Growth," art. cit.

${ }^{15}$ D. Sull and C. Sull, "With Goals, FAST Beats SMART," MIT Sloan Management Review, vol. 59, no. 4, 2018, pp. 1-11.
} 
and, most importantly, the purpose of the system. Indeed, well-developed objectives can be very useful, and, in most of the cases, they are necessary and compatible with management by missions (MBM). However, as Birkinshaw stated after analyzing companies that have maintained high levels of purpose and profitability over time (e.g., Tata, HCL Technologies, Novo Nordisk and Whole Foods), the objectives systems, alone, cannot generate a sense of purpose; it also needs elements that reinforce and prevent the system from focusing exclusively on financial results. ${ }^{16}$

\section{Low-Octane Cultures}

So long as the corporate purpose continues to be (or perceived to be) exclusively to maximize shareholder value, companies will not realize people's full potential. ${ }^{17}$ Alternatives such as corporate social responsibility may generate a certain sense of pride of belonging that is useful for employer branding, but these are not solutions that inspire genuine commitment to the enterprise. The solution must revolve around a purpose that is consistent, coupled with the values of authenticity and integrity that promote a sense of mission in the workplace. However, that is easier said than done. Many companies have the right pieces of the puzzle but struggle putting them together.

It is one thing to define a specific culture (purpose, values, principles, policies...) but quite another to implement it effectively. This reality can be seen, on a global scale, in various studies. The latest Gallup polls on employee engagement (a critical measure of competent culture), with 6.5 million respondents from 155 countries in every continent, ${ }^{18}$ for example, provide a snapshot of the current situation that distinguishes three types of employees:

\footnotetext{
${ }^{16}$ J. Birkinshaw, N.J. Foss and S. Lindenberg, "Combining Purpose with Profits," art. cit.

${ }^{17}$ S. Lindenberg and N.J. Foss, "Managing Joint Production Motivation: The Role of Goal Framing and Governance Mechanisms," Academy of Management Review, vol. 36, no. 3, 2011, pp. 500-525. ${ }^{18}$ See: https://www.gallup.com/workplace/238079/state-global-workplace-2017.aspx. [Referenced: $11 / 9 / 2020]$
} 
Table 3.1 Status of the global workplace (Gallup)

\begin{tabular}{lll}
\hline Actively disengaged (\%) & Not engaged (\%) & Engaged (\%) \\
\hline 18 & 67 & 15 \\
\hline
\end{tabular}

- Engaged. Employees are highly involved in, enthusiastic about and committed to their work and workplace; they drive performance and innovation, move the organization forward.

- Not engaged. Employees are psychologically unattached to their work and company and who put time, but not energy or passion, into their work.

- Actively disengaged. Those who have miserable work experiences because their needs are not being met.

Of the total sample, only $15 \%$ are engaged at work; two-thirds do not feel engaged (67\%); and 18\% are actively disengaged (Table 3.1).

This reality has also been the focus of our study of more than 200 companies from a range of sizes and sectors. Using surveys and interviews, we have confirmed that, despite the efforts many companies make to develop their own culture, they mostly fall short. These are some of the main cultural issues:

- Unfamiliarity with the company's purpose. Although many of the sample companies have some sort of formal statement of principles and priorities, few employees really know them, and even fewer feel that they impact their daily work.

- Lack of faith in the organization's values. Very often, the organizational values have no credibility. Employees are either unaware of them or see a discrepancy between what the company "preaches" and what it "practices."

- Inadequate top-down communication. Most of the companies surveyed have communication tools (some even have communication departments), and yet communication is seen as inadequate or confusing, especially at lower levels of the organization.

- Inadequate horizontal communication. Information does not flow naturally across departments. People regularly complain that departments don't want to share information. This makes life difficult for both sides. Some perceive this as an invisible barrier that makes areas opaque to one another. 
- Lack of cooperation. Each area is a silo; cooperation takes place only on certain preestablished issues, or when group work makes it inevitable. People do not proactively pursue cooperation. Everyone "does their own thing" and they only take notice of others when they have a problem or are looking for someone to blame.

- Resistance to change. Despite living in an increasingly changing environment, employees are reluctant to adapt to changes. This stifles decision-making processes and the ability to respond to market needs.

These findings show that companies have much room for improvement in the cultural realm, and companies in general have a lack of cultural strength ("low-octane cultures").

\section{Beyond Management by Objectives}

We believe to achieve greater culture; companies must establish a new organizational context-one that focuses on a transcendental aim and offers meaning to people's work through a shared sense of purpose. Such a culture is not going to come from clever slogans or management speeches: to be sure, it will require a renewed management methodology that can, once and for all, surpass the limitations of MBO. It is no longer a matter of exercising tighter control or piling on the pressure; it's about getting people to feel more committed and motivated, so that they have a sharper sense of urgency and learn to set their sights beyond strictly personal objectives. When people work with a shared sense of purpose, they do not try to build a sandbag for themselves; nor do they content themselves with preestablished objectives. Even more importantly, they work naturally as a team.

This is not an unrealistic scenario, nor is it unattainable in practice. On the contrary, it is the context in which we humans naturally seek to freely realize our full potential. It is the context we find in family, friendship or play. In contexts such as these, people feel united precisely because they share a purpose. They find it perfectly natural to strive for a common goal (transcendent motivation). That is because, maybe without realizing it, their actions are aligned to a purpose, and they understand at a deeper level what it is all for-a goal beyond their own extrinsic needs. 
It is sad to see how, in a business context ruled by the tyranny of profit maximization, many of these people become rabidly opportunistic, vengeful, distrustful and calculating. It is sad, not only because of the waste of human potential but even more because of the unhappiness the resulting impoverishment causes in these people. The solution is not to turn companies into amusement parks or put more ping-pong tables in the employee break room. It is about giving value to people's work that goes beyond shareholder earnings and inspires real engagement.

Management by missions does not imply a complete departure from $\mathrm{MBO}$; as many experts claim, the solution is not to eliminate objectives, but to develop a new management approach based on a transcendental purpose. ${ }^{19}$ To provide a greater understanding of MBM, the next chapter delves deeper into company purpose and how that purpose should be defined to achieve genuine employee engagement.

\section{"We Were Missing Something..."}

Industrial Química del Nalón is an Asturian company in the coal chemical industry belonging to Grupo Orejas, a multi-industry conglomerate. Founded in 1943, shortly after the Spanish Civil War, the company managed to survive over the years to become one of the leading chemical companies in the region, with a broad presence in the international market.

In the early 2000s, seeking to professionalize its management and streamline production processes, the company undertook various change programs based on management by objectives (MBO) and lean manufacturing tools. The changes brought good results from a financial perspective, along with considerable savings and far greater productivity and efficiency. However, within a few years, the management team realized that these improvements were starting to plateau. The new tools were not helping it get over the hurdle of organizational culture, which was highly unionized and made it difficult to establish leadership among the teams.

In 2011, the company turned to management by missions (MBM), hoping that the human dimension-ever present in the principles of the company and its shareholders-would spread throughout the organization and

(continued)

\footnotetext{
${ }^{19}$ S. Lindenberg and N.J. Foss, "Managing Joint Production Motivation," art. cit., pp. 500-525.
} 


\section{(continued)}

inspire its workers in everything they were doing. Jaime González-Baizán, the company's CEO from 2007 to 2019, shared his experience: ${ }^{20}$

"We had to modernize a number of processes. The company had tremendous technological and industrial strengths, but in other areas, it had major weaknesses. We were extremely focused on the technical side, but not so much on the people. A lot of departments were siloed. Those last few years, we used lean manufacturing to launch a series of programs and workshops. We started to implement what we call DOPA, ${ }^{21}$ a way to deploy objectives at different levels so we could connect everyone to the company's objectives. We implement $5 \mathrm{~S}^{22}$ troubleshooting tools, Lean Six Sigma" ${ }^{23}$ and autonomous work teams. We did a lot there, as you can see.

"Everything worked, and it brought considerable savings every year, but we still had problems. Honestly, it was hard for us to achieve the objectives, and we couldn't come up with a scorecard that would work for us in practice, because people just didn't see the value in it. What I realized is that knowing the technical part didn't actually generate unity or leadership. We were missing something. And that's when we discovered management by missions.

"Delving deeper into missions has helped us understand our 'reason for being' as a company. It makes it easier for us to sift through opportunities and initiatives... Before that, we analyzed everything that came up. Now we ask ourselves: Does it align with our missions or not? This way, we have a clear vision of why we are here. It has broadened the perspective of departments and their managers. For example, before it was hard to see how Sales had an important role in HR or that Finance had an important role in customer service and relationships. We started to view our work differently. The method of defining objectives has improved substantially, and I think that's a good barometer. It's also noticeable on the scorecard. Now, all departments have their own scorecard; they know where it came from and, most importantly, they know why they need it. This has brought our people, departments and factories closer together. You start looking for a lot more reasons to be together, and I think that's great."

(continued)

\footnotetext{
${ }^{20}$ Jaime González-Baizán passed away in October 2019 at the age of 56. This testimonial is a compilation from the talk he gave at the 4th Meeting of companies of the UIC's Chair of Management by Missions and Corporate Purpose, on November 21, 2013.

${ }^{21}$ Deployment of objectives and plan of action.

${ }^{22}$ The $5 \mathrm{~S}$ philosophy has its roots in Japan. The name " $5 S$ " is the acronym for five Japanese words with the following meanings: seiri (sort), seiton (store), seiso (shine), seiketsu (standardize) and shitsuke (sustain).

${ }^{23}$ Six Sigma $(6 \sigma)$ is a process improvement strategy.
} 


\section{(continued)}

Using management by missions, the management team launched several leadership and coordination programs between the different areas. New challenges and initiatives were undertaken, both for business development and for diversification into other businesses. In just a few years, after strongly promoting organizational unity and team leadership, the company had become far more efficient in its processes, created solid long-term relationships with its customers and main suppliers and, consequently, achieved excellent financial results.

"At the end of the day," added Jaime, "missions have to be at the heart of the work and the company itself. Management by missions is not an event; it's something each person has to bring to their daily work. It's important to get buy-in from the skeptics and reach everyone. The more you work on management by missions, the more you realize that if people are at the heart of the company, then you have to put a lot more effort on the people side. The challenge is to figure out how we get the workers to focus on the missions and ensure that each team has team-specific missions that reflect how they contribute to the overall company missions."

Open Access This chapter is licensed under the terms of the Creative Commons Attribution 4.0 International License (http://creativecommons.org/licenses/ by/4.0/), which permits use, sharing, adaptation, distribution and reproduction in any medium or format, as long as you give appropriate credit to the original author(s) and the source, provide a link to the Creative Commons licence and indicate if changes were made.

The images or other third party material in this chapter are included in the chapter's Creative Commons licence, unless indicated otherwise in a credit line to the material. If material is not included in the chapter's Creative Commons licence and your intended use is not permitted by statutory regulation or exceeds the permitted use, you will need to obtain permission directly from the copyright holder.
